\title{
An Ergonomic Questionnaire Survey on the Use of Computers in Schools
}

\author{
Midori SOTOYAMA $^{1 *}$, Ulf BERGQVIST ${ }^{2}$, Hiroshi JONAI ${ }^{1}$ and Susumu SAITO ${ }^{1}$
}

\author{
${ }^{1}$ National Institute of Industrial Health, 21-1, Nagao 6, Tama-ku, Kawasaki 214-8585, Japan \\ ${ }^{2}$ National Institute for Working Life, S-17184, Solna, Sweden
}

Received December 24, 2001 and accepted February 19, 2002

\begin{abstract}
A questionnaire was sent out to elementary, junior high and high schools in Yokohama and Kawasaki Cities from January to March 1998 regarding the use of personal computers by pupils and students. The survey included the questions that asked how often and in what environment computers are used, whether any instructions are given as to their use, children's working posture, and the effect on health. The results show that most schools are slow to develop instructive programs from the environmental or ergonomic point of view. So far there are not many children who complain of any serious symptoms such as pain in the neck, head or shoulders, but a future increase in the number of classes which involve computing, as well as the widespread popularity of home computers, will surely arouse a legitimate concern about the health of pupils and students, since they will spend more and more time operating the devices. An effective way to anticipate the problem is to provide young students with adequate knowledge of easy-on-body usage and environmental design, and now there is an urgent need for specific guidelines to protect them.
\end{abstract}

Key words: VDT work, Computer, Ergonomic Education, Student, Effects on Health, Questionnaire

\section{Introduction}

Since the early 1990s many countries have included computer education in their school curricula. Japan has the reformed National Curriculum Standards published from 1998 to 1999, which require that junior high school students learn information-related matters as part of their Industrial Arts and Homemaking course from 2002, and a new obligatory course of Information Study be established in high schools from 2003. While no special subject is set for elementary school children under these reformed National Curriculum Standards, consideration is called for to "enrich their educational activities to help them become familiar with, and properly use, computers, informationcommunication networks and other information media". In compliance with these official requirements, each school is now acquiring computer devices and rapidly paving the way for curriculum reorganization.

*To whom correspondence should be addressed.
Personal computers had been introduced into workspaces early in the 1970s, prior to use in schools. Displays and keyboards, whose optical and physical characteristics are totally different from those of paper and pencil, caused a sharp increase in the number of users experiencing eye fatigue, pain or dryness, shoulder stiffness, and back and low back pain. Among the many subsequent surveys and experimental studies, Saito observed that when working at a computer one's posture tends to become more tightly restrained and eye movement busier than when writing with "pencil and paper"), Sotoyama noted that the ocular surface area, the surface area of the eyeball which exposed to the air, increases due to upward gaze ${ }^{2)}$, and Abe pointed out a decrease in tears during upward gaze ${ }^{3)}$ all referred to as among causative factors in shoulder stiffness or eye pains.

Based on these findings, suggestions have been made as to device requirements, how to use computers with less strain on the body and how to design an ergonomically good computer environment ${ }^{4-8)}$.

The adoption of computers in schools is proceeding apace 
now, but is the accumulated know-how utilized in any effective way? If such rapid adoption continues without due consideration of users, there is a chance that some pupils and students will suffer from physical disorders, just as adults did on the computerization of office work.

We saw the need for recognizing the current state of the computer environment and usage, and this constituted the motivation for the said questionnaire survey which included the ergonomic viewpoint.

\section{Methods}

The subjects were 100 elementary schools, 50 junior high schools and 50 high schools, selected randomly from among the elementary, junior and high schools in Yokohama and Kawasaki Cities, including both public and private. Copies of the questionnaire entitled "A Questionnaire on Computers and Their Use in Schools" were sent out to be received by the teachers who were engaged in computer education but not expert in computer handling. Two copies were sent to each elementary school, one for the lower graders (1-3) and one for the higher graders (4-6). Each junior high and high school received one copy. The term of the survey was from January to March 1998.

\section{Results}

The response rate was $75 \%$ for elementary, $80 \%$ for junior high and $68 \%$ for high schools.

Questions 1 to 3 in the tables show the results which include all the schools that responded the questionnaire, and Q4 to Q23 include only those schools which had already introduced computers into their curricula. In the latter case, the number of schools already using computers is counted as $100 \%$, each reported percentage being the ratio of the number of schools whose answers fell into the corresponding group to the number of schools already using computers.

\section{Questions concerning computer education and its contents $(Q 1-Q 5)$}

The results are shown in Table 1.

Q1: The average numbers of students per school in elementary, junior high and high schools are around 500, 550 and 900 , respectively.

Q2, Q3: As of March 1998, the schools that had adopted computers constituted $40 \%$ of the elementary, $90 \%$ of junior high schools and $70 \%$ of high schools. About $10 \%$ of the junior high and high schools answered that they are "making positive efforts in computer education". Relatively higher- grade classes had adopted computers earlier than lower-grade classes in the same school.

Q4: The main teaching focus was on graphics for elementary lower-grades pupils, word-processing and graphics for both elementary higher-grades and junior high students, and programming and word-processing for high school students. About $20 \%$ in each category had introduced Internet education.

Q5: Only several percent in each category of schools answered that they were actively teaching the students in an appropriate environment that they should use a computer. About $30 \%$ of the elementary and high schools, and about $60 \%$ of junior high schools answered that they were doing that "within a limited scope". Those which were "not at all" making such efforts exceeded $60 \%$ in both elementary and high schools.

\section{Questions concerning how computers are used (Q6-Q10)}

The results are shown in Table 2.

Q6: Among those schools which had computer-related curricula, about $40 \%$ of the elementary and more than $90 \%$ of the junior high and high schools had special rooms for computers. Although a total of $50 \%$ were provided with an Internet-accessible machine environment, comparison with Q4 shows that not all of them were utilizing it in Internet education.

Q7: The number of computers installed was nearly one for every 10 to 20 pupils or students.

Q8: The higher the grade, the higher the percentage of schools in whose computer classes at least one computer was available for each pupil or student. In almost $100 \%$ of the elementary schools one computer was shared by more than 2 users at a time, and it was 2 to 3 users per computer in more than $90 \%$ of junior high schools; whereas in contrast, nearly $70 \%$ of high schools made it possible for each student to use a machine for him or herself.

Q9: The higher the grade, the longer the hours per week a pupil or student worked at a computer. In $90 \%$ of the elementary and junior high schools the use of a computer did not exceed 2 hours per week, whereas in about $30 \%$ of the high schools it did exceed 2 hours.

Q10: Pupils and students were not permitted the free use of computers during breaks or after hours, except in less than $40 \%$ of each school category.

\section{Questions concerning computer equipment (Q11-Q14)}

The results are shown in Table 3.

Q11-13: While desktop machines were mainly used in more than $90 \%$ of each junior high and high school, the portable 
Table 1. Questions concerning computer education and its content

Q1. How many students are there in your school?

\begin{tabular}{lc}
\hline & Number of students \\
\hline Low grade & 243 \\
High grade & 263 \\
Junior high & 553 \\
High school & 885 \\
\hline
\end{tabular}

Q2. Are you carrying out computer education - for example on how to use the INTERNET?

\begin{tabular}{lccc}
\hline & None & Limited & Extensive $(\%)$ \\
\hline Low grade & 72 & 25 & 3 \\
High grade & 55 & 43 & 3 \\
Junior high & 13 & 78 & 10 \\
High school & 32 & 53 & 15 \\
\hline
\end{tabular}

Q3. Are computers used as tools in the teaching of other subjects?

\begin{tabular}{lccc}
\hline & None & Limited & Extensive $(\%)$ \\
\hline Low grade & 75 & 21 & 4 \\
High grade & 59 & 35 & 5 \\
Junior high & 30 & 68 & 3 \\
High school & 38 & 59 & 3 \\
\hline
\end{tabular}

Q4. If the answer to question 2 is "limited" or "extensive", is computer education given concerning?

\begin{tabular}{lccccc}
\hline & Programming & $\begin{array}{c}\text { Word } \\
\text { processing }\end{array}$ & $\begin{array}{c}\text { Image/picture } \\
\text { handling }\end{array}$ & Internet & Other (\%) \\
\hline Low grade & 0 & 41 & 82 & 14 & 32 \\
High grade & 3 & 83 & 86 & 26 & 43 \\
Junior high & 25 & 81 & 81 & 14 & 14 \\
High school & 44 & 64 & 44 & 20 & 40 \\
\hline
\end{tabular}

Q5. Is education given in computer ergonomics (i.e. how to design a computer work station, how to sit, how to arrange lighting etc.)?

\begin{tabular}{lccc}
\hline & None & Limited & Extensive $(\%)$ \\
\hline Low grade & 64 & 32 & 5 \\
High grade & 63 & 37 & 0 \\
Junior high & 31 & 64 & 6 \\
High school & 60 & 32 & 4 \\
\hline
\end{tabular}

(notebook) models were more available in nearly $80 \%$ of the elementary schools. Cathode Ray Tube Displays (CRTs) for desktops and Liquid Crystal Displays (LCDs) for notebooks, both generally color were the most usual combinations.

Q14: Keyboards and a mouse were the typical input devices.

\section{Questions concerning ergonomic considerations (Q15- Q19)}

The results are shown in Table 4.
Q15-17: Desks and chairs specially designed for young people were adopted by $40 \%$ of the junior high schools and $20 \%$ each of the other groups. Height-adjustable desks were seldom used in any group, but height-adjustable chairs were common in junior high and high schools (90\% each). Fixedheight chairs were used in more than $70 \%$ of the elementary schools.

Q18, 19: Consideration of lighting (e.g., the position of windows and lighting fixtures) was included by $40 \%$ of the elementary and high schools, and also by $60 \%$ of the 
Table 2. Questions concerning how computers are used

Q6. Does your school have

a. A special room for computers?

b. Computers placed in classrooms?

c. Computers placed in the vicinity of classrooms?

d. Computers linked to nets within the school?

e. Computers linked to external nets such as the INTERNET?

\begin{tabular}{lrrrrr}
\hline & $\mathrm{a}$ & $\mathrm{b}$ & $\mathrm{c}$ & $\mathrm{d}$ & $\mathrm{e}(\%)$ \\
\hline Low grade & 45 & 23 & 41 & 18 & 50 \\
High grade & 34 & 17 & 34 & 11 & 40 \\
Junior high & 100 & 3 & 36 & 14 & 44 \\
High school & 92 & 0 & 20 & 28 & 60 \\
\hline
\end{tabular}

Q7. How many computers are there in the school for student use?

\begin{tabular}{lcc}
\hline & $\begin{array}{c}\text { Number of } \\
\text { computers }\end{array}$ & $\begin{array}{r}\text { Computers } \\
\text { per student }\end{array}$ \\
\hline Low grade & 13 & 0.09 \\
High grade & 12 & 0.06 \\
Junior high & 23 & 0.05 \\
High school & 50 & 0.05 \\
\hline
\end{tabular}

Q8. How many students use a computer at the same time?

Normally one

Normally 2-3 together

Normally more than 3 together

\begin{tabular}{lrrrr}
\hline & One & $2-3$ & $>3$ & $(\%)$ \\
\hline Low grade & 9 & 41 & 59 & \\
High grade & 3 & 37 & 60 & 0 \\
Junior high & 6 & 94 & 0 \\
High school & 68 & 20 & 12 \\
\hline
\end{tabular}

Q10. Can the students use the computers when they choose?

\begin{tabular}{lc}
\hline & Yes $(\%)$ \\
\hline Low grade & 41 \\
High grade & 34 \\
Junior high & 11 \\
High school & 28 \\
\hline
\end{tabular}

junior high schools.

\section{Questions concerning health $(Q 20-Q 23)$}

The results are shown in Table 5.

Q20: Almost 50\% in each group provided some instruction on working posture. As far as the junior high school group is concerned, nearly half were also giving some guidance as to the height of chairs and viewing angle. This group scored highest on the greater part of instruction-related questions.

Q21: Students complaining of eye pain or eye discomfort were reported in more than $20 \%$ of the junior high and high schools. The higher the grade, the greater the number of students experiencing these and other symptoms.

Q22: Regardless of school categories, almost half the
Q9. How long does - in your experience - a student normally use a computer in school each week?

\begin{tabular}{lcccc}
\hline & $0-2$ & $2-4$ & $4-6$ & $>6$ hours/week $(\%)$ \\
\hline Low grade & 95 & 5 & 0 & 0 \\
High grade & 89 & 9 & 0 & 0 \\
Junior high & 92 & 6 & 0 & 3 \\
High school & 68 & 20 & 8 & 0 \\
\hline
\end{tabular}

respondents observed that some pupils and students were apt to keep too short a viewing distance. The most conspicuous example of bad posture assumed by elementary and junior high children was that of slouching forward, whereas more than $30 \%$ of the high schools, in contrast, had noted such a far-backward posture that the user is virtually lying on his or her back.

Q23: The pupils and students complaining of eye problems were a low percentage, but steadily growing in number among higher graders.

\section{Discussion}

At the time of the survey in March 1998, the schools which 
Table 3. Questions concerning computer equipment

What type of computers are in use? (You may respond to several alternatives if appropriate.)

Q11. “Normal” computers (i.e. one that normally stays in one place)—Desktop

Notebook (i.e. one that is normally carried around)

Q12. Is the most common a Cathode Ray Tube (TV-like)

....or a liquid crystal screen (LCD)

....or other(s)

Q13. Is it most common to have single colour screens (bl/w) ....or multicolour screens

\begin{tabular}{lccrrrr}
\hline & \multicolumn{2}{c}{ Q11 } & \multicolumn{2}{c}{ Q12 } & \multicolumn{2}{c}{ Q13 } \\
& Desktop & Notebook & CRT & LCD & bl/w & multicolour (\%) \\
\hline Low grade & 55 & 73 & 55 & 68 & 0 & 100 \\
High grade & 46 & 77 & 46 & 74 & 0 & 100 \\
Junior high & 100 & 8 & 100 & 8 & 3 & 100 \\
High school & 92 & 20 & 92 & 20 & 12 & 92 \\
\hline
\end{tabular}

What type of equipment for data entry is used?

(You may respond to several alternatives if appropriate.)

Q14. Data entry is most often by use of

\begin{tabular}{lccccc}
\hline & Keyboard & Mouse & Trackball & Touchpad & Other (\%) \\
\hline Low grade & 91 & 100 & 5 & 0 & 5 \\
High grade & 97 & 100 & 6 & 9 & 0 \\
Junior high & 100 & 100 & 3 & 3 & 3 \\
High school & 100 & 96 & 0 & 0 & 0
\end{tabular}

Table 4. Questions concerning ergonomic considerations

Q15. Do the students use tables and chairs designed for children?

Q16. Can the students normally adjust the table height?

Q17. Can the students normally adjust the chair height?

\begin{tabular}{lccc}
\hline & Q15 & Q16 & \multicolumn{2}{l}{ Q17 } \\
& Yes & Yes & Yes $(\%)$ \\
\hline Low grade & 18 & 0 & 27 \\
High grade & 23 & 3 & 20 \\
Junior high & 36 & 8 & 97 \\
High school & 16 & 4 & 88 \\
\hline
\end{tabular}

Q18. Has window position been considered when placing the computers?

Q19. Has the position of lighting been considered when placing the computers?

\begin{tabular}{lll}
\hline & Q18 & Q19 \\
& Yes & Yes $(\%)$ \\
\hline Low grade & 41 & 27 \\
High grade & 40 & 29 \\
Junior high & 50 & 67 \\
High school & 36 & 40 \\
\hline
\end{tabular}

already introduced computer education accounted for around $40 \%, 90 \%$ and $70 \%$ of the elementary, junior high and high schools, respectively. The focus of teaching varies from one school group to another, but the percentage of schools which were "making positive efforts in computer education" was nearly the same in all the groups, about one tenth of the total. It is reasonably expected that the last few years have added to the above figures, giving a chance for more schools to start and get more actively engaged in computer education programs.

Regarding computer hardware, it is remarkable that more than $70 \%$ of the elementary schools were letting their pupils work with LCD-integrated notebook computers. Since notebooks tend to put priority on portability even when it could compromise comfort for users ${ }^{4)}$, it is desirable to switch to desktops if there is enough space in the classroom.

To take just a few examples, a desktop computer has a keyboard slightly tilted so that the tilt may mitigate the strain on the operator's hands, while a notebook type offers no such comfort. Instead, the latter has, as Saito pointed out, not only the keyboard but also the display integrated into its main body, thus often causing the user to secure an easy access to the keyboard by placing it in a way that leaves only a short viewing distance ${ }^{9}$. Moreover, views on LCDs are dependent on the viewing angle ${ }^{4)}$, that is, not clear or in proper colours when seen from oblique angles-a characteristic which becomes a disadvantage when one notebook is shared by more than two persons. Thus notebook computers with an integrated display and keyboard can therefore put heavier strain on the user's musculoskeletal and visual systems ${ }^{10)}$. Desktops with a CRT are preferable, especially if shared by two or more users at once.

Less than half of the schools were taking care to place displays with regard for their relative position to windows and lighting fixtures. Light would help, if viewed objects were something written on paper such as books or notebooks, but it would rather have adverse effects with CRTs or backlight LCDs. Being luminescent in their own right, 
Table 5. Questions concerning health

Q20. Are the students given any advice when they use computers concerning

a. Seating posture

b. Chair height

c. Table height

d. Viewing angle

e. Lighting

f. Other advice

\begin{tabular}{lccrccc}
\hline & $\mathrm{a}$ & $\mathrm{b}$ & $\mathrm{c}$ & $\mathrm{d}$ & $\mathrm{e}$ & $\mathrm{f}(\%)$ \\
\hline Low grade & 45 & 14 & 5 & 27 & 18 & 9 \\
High grade & 49 & 14 & 6 & 20 & 17 & 14 \\
Junior high & 56 & 58 & 17 & 42 & 14 & 14 \\
High school & 36 & 12 & 4 & 28 & 16 & 16 \\
\hline
\end{tabular}

Q21. Do students experience discomfort when using computers?

a. Yes, eye discomfort

b. Yes, neck or shoulder

c. Yes, arm or hand

d. Yes, back

e. Yes, other

f. No, I don't know of any

\begin{tabular}{lrrrrrr}
\hline & $\mathrm{a}$ & $\mathrm{b}$ & $\mathrm{c}$ & $\mathrm{d}$ & $\mathrm{e}$ & $\mathrm{f}(\%)$ \\
\hline Low grade & 5 & 0 & 0 & 0 & 0 & 95 \\
High grade & 6 & 0 & 0 & 0 & 0 & 91 \\
Junior high & 19 & 3 & 0 & 0 & 3 & 81 \\
High school & 24 & 4 & 8 & 0 & 4 & 68 \\
\hline
\end{tabular}

Q22. Have you noticed body postures such as

a. very short distance to the computer

b. the student looks "upwards" to the computer

c. "abnormal" neck position (head back)

d. collapsed position (forward)

e. extreme reclining position (half lying backwards)

\begin{tabular}{lrrrrl}
\hline & $\mathrm{a}$ & $\mathrm{b}$ & $\mathrm{c}$ & $\mathrm{d}$ & $\mathrm{e}(\%)$ \\
\hline Low grade & 50 & 18 & 5 & 23 & 14 \\
High grade & 51 & 6 & 3 & 26 & 11 \\
Junior high & 72 & 3 & 8 & 22 & 14 \\
High school & 44 & 12 & 12 & 8 & 32 \\
\hline
\end{tabular}

Q23. Have you noticed - in students - eye problems such as
a. red eyes
b. excessive tears
c. frequent or intense eye rubbing
d. difficulty in reading words and/or symbols

\begin{tabular}{lcccc}
\hline & $\mathrm{a}$ & $\mathrm{b}$ & $\mathrm{c}$ & $\mathrm{d}(\%)$ \\
\hline Low grade & 0 & 0 & 5 & 0 \\
High grade & 0 & 0 & 0 & 6 \\
Junior high & 0 & 3 & 0 & 14 \\
High school & 4 & 4 & 0 & 16 \\
\hline
\end{tabular}

displays, like TV, will have their visibility impaired by lighting. Glare caused by highly-luminescent reflections of windows or fluorescent tubes will become an inducement to eye fatigue. That is why such precautions should be taken as attaching adjustable window shades to gain appropriate lightness anytime, or seeking to avoid reflections by the desirable positioning of displays, windows and lighting fixtures.

Akutsu's report based on a survey regarding working postures of elementary pupils before computers mentioned unsuitable workstation conditions in view of children's physique: short viewing distance, feet hanging above floors, chair backs too far back to support the body ${ }^{11)}$. Working for hours under such conditions will surely result in severe eyestrain, pressure on feet and heavy stress on back and shoulders.

Our survey also revealed that many elementary school pupils assume bending, head-forward postures with upward gaze (Q22), probably reflecting the situation where they are striving to see the displays set too high for children's eyes. Taptagaporn ${ }^{12)}$ and Sotoyama ${ }^{13)}$, having identified upward gaze as a source of extra physical strain which in turn causes pain and dryness in the eyes, recommended the use of heightadjustable desks and chairs that allow children to assume higher postures and look down on the screen.

In elementary schools, where smallness of the adoption ratio of height-adjustable chairs was especially noted, emphasis must be laid on creating a flexible environment that accommodates the needs of every young student. Such efforts must pay attention to the great difference in physique not only between lower and higher grades but also among individuals. Since this issue of physical individuality is common to other categories, it is desirable for all schools to introduce height-adjustable desks and chairs and provide each student with the most suitable computer operating environment.

This time the survey did not reveal any serious effects on the health of pupils or students. Presumably this is mainly because their use of computers did not exceed two hours a week in most of the schools.

According to the recent wide-ranging questionnaire survey covering a variety of job categories ${ }^{14)}$, approximately $80 \%$ of the working people were experiencing some form of physical fatigue or subjective symptoms that could be ascribed to the use of computers. If pupils and students should come to spend more school hours working at computers, it is possible that more of them will experience physical fatigue or other subjective symptoms. As an effective way to prevent such future situations, an installation 
plan for computers should include the choice of chairs, desks, input devices and displays that meet the ergonomic requirements, as well as due consideration of the natural and artificial lighting. Even if some of these may not be feasible, for example, for financial reasons, knowing the ergonomic way of thinking will help to reduce body strain by using simple tools or ideas.

\section{Conclusion and Future Agenda}

Within the scope of this survey, those schools that were "teaching the pupils and students in an appropriate environment how to use a computer" accounted for $40 \%$ of the elementary and high schools and $60 \%$ of the junior high schools. On the other hand, less than $10 \%$ in each school category were doing that "actively".

Now that the amount of computer time at home and school is sure to keep increasing, the important thing is to use the equipment in a well-designed environment, benign and attuned to human behavior, physiology and psychological features, in order to maintain users' health. It would be most effective and useful for pupils and students to acquire in their classrooms the necessary knowledge for creating such an environment. But the guidelines for pupils and students ${ }^{15)}$ are very few. The current guidelines and international standards are possible teaching materials. But since they have been devised for adults, they are not always applicable to or detailed enough for young computer users. It is a matter of urgency that we develop new guidelines based on attention given to the physique and physiology of pupils and students.

\section{References}

1) Saito S, Taptagaporn S, Salvendy G (1993) Visual comfort in using different VDT Screens. International Journal of Human-Computer Interaction 5, 313-23.

2) Sotoyama M, Villanueva MBG, Jonai H, Saito S (1995) Ocular surface area as an informative index of visual ergonomics. Ind Health 33, 43-56.

3) Abe S, Sotoyama M, Taptagaporn S, Saito Sh, Villanueva MBG, Saito S (1995) Relationship between vertical gaze direction and tear volume. Work with Display Unit: 95-9.
4) Saito S, Piccoli B, Smith MJ, Sotoyama M, Sweitzer G, Villanueva MBG, Yoshitake R (Technical Committee on Human-Computer Interaction, International Ergonomics Association, IEA) (2000) Ergonomic guidelines for using notebook personal computers. Ind Health 38, 421-34.

5) International Organization for Standization (1992) ISO 9241 series: Ergonomics requirements for office work with visual display terminals (VDTs).

6) International Organization for Standization (1999) ISO 13406-1:Ergonomic requirements for work with visual displays based on flat panels-Part 1: Introduction.

7) Japanese Industrial Standards Committee (1994) JIS Z 8513:Ergonomics-Office work with visual display terminals (VDTs) — Visual display requirements.

8) Ministry of Labour (1985) Official notice of VDT work guideline.

9) Saito Sh, Miyao M, Kondo T, Sakakibara H, Toyoshima H (1997) Ergonomic evaluation of working posture of VDT operation using personal computer with flat panel display. Ind Health 35, 264-70.

10) Villanueva MBG, Jonai $H$, Sotoyama $M$, Hisanaga $N$, Takeuchi Y, Saito S (1997) Sitting posture and neck and shoulder muscle activities at different screen height settings of the visual display terminal. Ind Health $\mathbf{3 5}$, $330-6$.

11) Akutsu S, Yatani M (1999) The charasteristics of computer operation by primary school children and ergonomic improvements of the workstation. The Japanese Journal of Ergonomics 35 (Supplement 2), 532-3.

12) Taptagaporn $S$, Saito $S$ (1993) Visual comfort in VDT operation: Physiological resting states of the eye. Ind Health 31, 13-28.

13) Sotoyama M, Jonai H, Saito S, Villanueva MBG (1996) Analysis of ocular surface area for comfortable VDT workstation layout. Ergonomics 39, 877-84.

14) Japan Industrial Safety and Health Association (1999) Industrial health management for VDT work. JISHA, Tokyo.

15) Williams IM (1999) Computer ergonomics for elementary school. http://www.orosha.org/cergos/ index.html. 